\title{
Bedah Sinus Endoskopik sebagai Pilihan Tata laksana Proptosis pada Mukosil Sinus Fronto-etmoidalis Asimetris Bilateral dengan Komplikasi
}

\author{
Desti Kusmardiani, Sinta Sari Ratunanda, Teti Madiadipoera \\ Departemen Telinga Hidung Tenggorok - Bedah Kepala Leher, Fakultas Kedokteran, Universitas Padjadjaran/ \\ Rumah Sakit Umum Pusat DR. Hasan Sadikin, Bandung
}

\begin{abstract}
Abstrak
Mukosil sinus paranasal merupakan lesi kistik pada sinus, dihasilkan dari akumulasi sekresi mukus dan deskuamasi epitel akibat obstruksi kronis dari osteum sinus. Mukosil memiliki sifat tumbuh lambat, sering di area sinus frontal dan etmoid, namun jarang terjadi bilateral asimetris. Mukosildapat menyebabkan distensi dinding sinus, sehingga dapat menimbulkan komplikasi ke area sekitarnya, terutama area mata. Dilaporkan satu kasus mukosil sinus fronto-etmoidalis asimetris bilateral dengan komplikasi orbita unilateral di Rumah Sakit Dr.Hasan Sadikin. Wanita 67 tahun dengan gejala klinis proptosis nonaksial pada orbita kanan, tanpa disertai diplopia, gangguan gerak bola mata maupun visus. Pasien memiliki riwayat bekerja di pabrik pembakaran genteng selama puluhan tahun. Metode pemeriksaan nasoendoskopi dan CT Scan menunjukkan mukosil bilateral asimetris pada sinus frontal-etmoid. Dilakukan prosedur pengangkatan mukosil dengan pendekatan marsupialisasi secara endoskopik. Pascaoperasi didapatkanhasil perbaikan gejala proptosis dan tidak terdapat rekurensi mukosil. Penatalaksanaan segera pembedahan endoskopik pada mukosil sinus frontoetmoidalis dapat memperbaiki komplikasi proptosis dengan morbiditas yang rendah dan luka operasi yang minimal, dibandingkan bedah terbuka.
\end{abstract}

Kata Kunci : Mukosil sinus frontoetmoidal, Proptosis, pembedahan endoskopi sinus

\section{Endoscopic Sinus Surgery as a Choice of Proptosis Management on Bilateral Asymmetrical Mucocele of Fronto-Ethmoidal Sinuses with Complication}

\begin{abstract}
Paranasal sinus mucocele are cystic lesion that affect the sinuses, it occurs from accumulation of mucoid secretion and desquamated ephitelium as a result from chronic obstruction of the sinus osteum. Mucosil has slowly progression, mostly in the frontal and etmoid sinus, but rarely bilateral asymmetries. Mucocele also can cause sinus wall distention, resulting complications to the surrounding area, especially ophtalmologic complication.Reported one case bilateral asymmetrical mucocele of the fronto-ethmoidal sinuses with unilateral orbital complicationin Hasan Sadikin Hospital. 67 years old women who presented with complaint of protrusion on her right eye without diplopia, eye ball movement disorder nor visus. She has a history of working in a tile burner for decades. Examination methods from nasoendoscopy and CT Scan showed bilateral asymmetrical mucocele at fronto-ethmoid sinuses. We performed mucocele extraction procedure with endoscopic marsupialitation approach.Postoperative obtained an improvement of protrusion and no reccurence. Immediate treatment with endoscopic surgery for frontoethmoidal sinus mucocele can improve proptosis complications with low morbidity and minimal surgical wound compared to open surgery.
\end{abstract}

Keywords : Frontoethmiodal sinus mucocele, Proptosis, endoscopic sinus surgery

Korespondensi:

Desti Kusmardiani

Departemen Telinga Hidung Tenggorok - Bedah Kepala Leher, Fakultas Kedokteran, Universitas Padjadjaran/

Rumah Sakit Umum Pusat DR. Hasan Sadikin, Bandung

Jl. Prof. Dr. Eyckman No. 38 Bandung 40161

Mobile : 081338350517

Email : dianides@gmail.com 


\section{Pedahuluan}

Mukosil pada sinus paranasal merupakan lesi ekspansif jinak dengan pertumbuhan lambat. Gambaran histopatologi mukosil merupakan kista yang dindingnya mempunyai struktur sama dengan epitel respiratori yang berisi cairan mukus. Mukosil juga didefinisikan sebagai lesi kronis, kistik dan jinak yang dapat mengenai bagian manapun dari sinus paranasal. Mukosil merupakan lesi destruktif yang dapat merusak tulang di sekitarnya dan dapat melibatkan struktur sekitarnya seperti orbita dan rongga intrakranial..$^{1,2}$

Mukosil dapat terjadi pada semua usia dan jenis kelamin, tetapi mayoritas pasien yang terdiagnosis pada usia 40 sampai 60 tahun.3Mukosil terbanyak pada sinus frontal (60$65 \%$ ), tetapi dapat juga ditemukan pada sinus etmoid (20-25\%), sinus maksila (10\%) dan sinus sphenoid (1-2\%). Komplikasi mukosisl berupa destruksi tulang dan ekstensi ke intrakranial dilaporkan sebesar $10-55 \% 0^{3,4}$

Penyebab mukosil masih belum diketahui dengan pasti. Obstruksi ostium sinus diduga merupakanpenyebabutama, sehinggaterjadiadhesi pascainflamasi, pascatrauma atau pascaoperasi. Faktor etiologi umum yang berhubungan dengan mukosil yaitu riwayat menderita sinusitis, riwayat menjalani operasi sinus, riwayat trauma maksilofasial, alergi, tumor, dan idiopatik. ${ }^{3}$

Mukosil terjadi akibat adanya obstruksi ostium sinus menyebabkan sinus meluas terisi cairan. Mukosil ini tumbuh lambat dan mengisi rongga sinus yang terkena, meluas dan mengerosi tulang yang berdekatan. Infeksi sekunder dapat menyebabkan ekspansi yang cepat dan meningkatkan komplikasi terutama di daerah periorbital. $^{3}$

Salah satu mekanisme pembentukan mukosil adalah degenerasi kistik kelenjar seromusinosa sehingga menyebabkan kista retensi. Massa yang besar seperti tumor atau polip juga dapat menyebabkan obstruksi ostium sinus. Produksi mukus yang terus-menerus di dalam mukosil menyebabkan mukosil bertambah besar sehingga memberikan tekanan pada dinding sinus. Pada proses lebih lanjut, mukosil dapat menyebabkan penipisan tulang dinding sinus sehingga dapat melibatkan struktur sekitar sinus seperti orbita. ${ }^{2,3,5}$

Beberapa teori yang menyelaraskan terjadinya erosi tulang pada mukosil karena adanya keterlibatan sitokin (IL-1) dari penekanan. Resorpsi tulang terjadi karena antigen merangsang pelepasan IL-1, sementara itu sel mononuklear yang terdapat pada periosteum mengeluarkan sitokin yang menghasilkan prostaglandin E2 (PGE2), sedangkan fibroblast menghasilkan kolagenase. PGE2 dan fibroblast menyebabkan terjadinya penyerapan tulang. Didapatkan kadar PGE2 dan kolagenase yang dihasilkan oleh fibroblast dalam mukosil dua kali lipat lebih banyak daripada mukosa normal. ${ }^{3,6}$

Secara histopatologi obstruksi dari resesus frontal yang disertai infeksi rongga sinus frontal, menstimulasi limfosit dan monosit yang menyebabkan produksi sitokin oleh lapisan fibroblast. Sitokin ini memicu resorpsi tulang sehingga menyebabkan ekspansi mukosil. Kultur fibroblast dari mukosil menunjukkan adanya peningkatan prostaglandin E2 dan kolagenase bila dibandingkan dengan fibroblast dari sinus frontal yang normal. Prostaglandin E2 juga memiliki peran utama dalam proses ostolitik di mukosil. ${ }^{5}$

Mukosil sinus frontal dapat memiliki ukuran dan konfigurasi yang bervariasi. Klasifikasi ini merupakan standar untuk mengevaluasi mukosil sinus frontal dan penatalaksanaannya, tipe I: mukosil hanya terbatas pada sinus frontal (dengan atau tanpa ekspansi ke orbita), tipe II: mukosil fronto-etmoid (dengan atau tanpa ekspansi ke orbita), tipe III: erosi dinding posterior sinus dengan ekspansi minimal atau tanpa ekspansi ke intrakranial ataupun ekspansi intrakranial yang luas, tipe IV: erosi dinding anterior, tipe V: erosi dinding posterior dan anterior dengan ekspansi minimal atau tanpa ekspansi intrakranial ataupun ekspansi intrakranial yang luas. ${ }^{5}$

Gejala klinis dari mukosil bervariasi tergantung daerah yang terkena. Gejala dapat berupa sakit kepala, nyeri daerah wajah, rasa penekanan di wajah, hidung tersumbat, dakriosistitis. Mukosil yang terinfeksi disebut mukopiosil dapat menyebabkan sinusitis, selulitis orbita, eritema, demam dan nyeri. Selain itu sering didapatkan massa yang teraba di daerah frontal atau di daerah kantus medius yang disertai proptosis. Ekspansi ke daerah orbita berupa proptosis, diplopia, penglihatan berkurang, epifora, nyeri kepala, serta benjolan pada daerah frontal atau wajah. Ekstensi intrakranial dapat menyebaban meningitis, abses subdural atau serebral, pneumosepalus, atau fistula likuor. ${ }^{4,7}$

Diagnosis mukosil ditegakkan berdasarkan anamnesis, pemeriksaan fisik, dan gambaran radiologik. Nasoendoskopi juga dapat digunakan untuk melihat adanya kelainan intranasal lainnya seperti poliposis, septum deviasi, dan lainlain. Diagnosis ditegakkan dengan pencitraan radiografi; standar emas dalam hal presisi diagnostik adalah computed tomography (CT), meskipun magnetic resonance imaging (MRI) sangat membantu dalam beberapa kasus. ${ }^{3,7,8}$

Tata laksana utama mukosil adalah pembedahan. Pembedahan dapat dilakukan 
melalui pendekatan eksternal seperti metode Riedel, Killian, Lynch-Howarth, Lothrop. Metode pembedahan lainnya adalah pendekatan transnasal endoskopik dan kombinasi pendekatan eksternal dan endoskopik. Pembedahan melalui transnasal endoskopik lebih disukai karena terkait dengan trauma minimal dan morbiditas yang lebih kecil. ${ }^{6,9,10}$

\section{Laporan Kasus}

Seorang wanita berusia 67 tahun dirujuk dari Rumah Sakit Mata Cicendo ke poli THT-KL Rumah Sakit Hasan Sadikin dengan diagnosis dari bagian mata yaitu proptosis nonaksial et causa tumor infra orbita suspek mukosil sinus frontalis et ethmoidalis. Keluhan utama mata sebelah kanan menonjol sejak dua tahun, tetapi kedua mata dirasakan masih normal. Keluhan disertai sakit kepala, terutama di daerah frontal kanan dan penurunan penghidu. Gejala hidung tersumbat, hidung beringus, post nasal drip, maupun epistaksis tidak ada. Tidak ada keluhan pada telinga maupun tenggorok. Riwayat alergi disangkal. Pasien memiliki riwayat bekerja di pabrik pembakaran genteng selama puluhan tahun.

Pada pemeriksaan fisik didapatkan proptosis non aksial mata kanan dimana bola mata kanan bergeser ke arah inferolateral, jarak antar pupil $48 \mathrm{~mm}$, dengan visus, gerak bola mata dan lapang pandang dalam batas normal. Teraba masa tumor di area epikantus medial kanan ukuran $2 \times 1 \times 1$ $\mathrm{cm}$ pada palpasi konsistensi kenyal dan terfiksir, tidak ada nyeri tekan. Pada pemeriksaan rinoskopi anterior kesan normal, pemeriksaan otoskopi dan pemeriksaan faringoskopi kesan normal.

Dari pemeriksaan naso endoskopi didapatkan mukosa dalam batas normal, konka inferior hipertrofi bilateral, sekret pada meatus medius dan dasar rongga hidung, tidak ada deviasi septum nasi, pada meatus media kanan terlihat masa hipervaskularisasi mendorong konka media ke arah medial.

Pemeriksaan laboratorium dan foto thoraks dalam ,batas normal, Pemeriksaan CT Scan kesan tampak lesi bulat, berbatas tegas, tepi regular gambaran mukosil sinus paranasal asimetris bilateral. Pada rongga hidung kanan mukosil cukup luas mengenai sinus frontal dan etmoid sehingga menekan bola mata dan mendorong bola mata kearah inferolateral. Pada rongga hidung kiri mukosil tampak setinggi ethmoid anterior tetapi tidak disertai peradangan bola mata. Tidak tampak ekstensi intrakranial pada kedua sisi.

Telah dilakukan marsupialisasi melalui pendekatan endoskopi, untuk pengangkatan mukosil. Pada intraoperatif, mukosil sisi kanan telah mendorong konka media sehingga menutupi ostium sinus maksilaris. Dilakukan unsinektomi sehingga mukosil lebih jelas terlihat. Mukosil diidentifikasi dan diaspirasi tampak cairan mukopurulen. Dinding mukosil yang teridentifikasi diinsisi selebar mungkin. Setelah prosedur marsupialisasi selesai, dilakukan pelebaran ostium sinus maksilaris. Hal serupa dilakukan pada sisi kiri.

Satu bulan pascaoperasi tidak ditemukan komplikasi. Proptosis mengalami perbaikan lebih bergeser ke arah mediosuperior, bola mata tidak terlalu menonjol, serta tidak ditemukan lagi masa yang teraba pada epikantus.

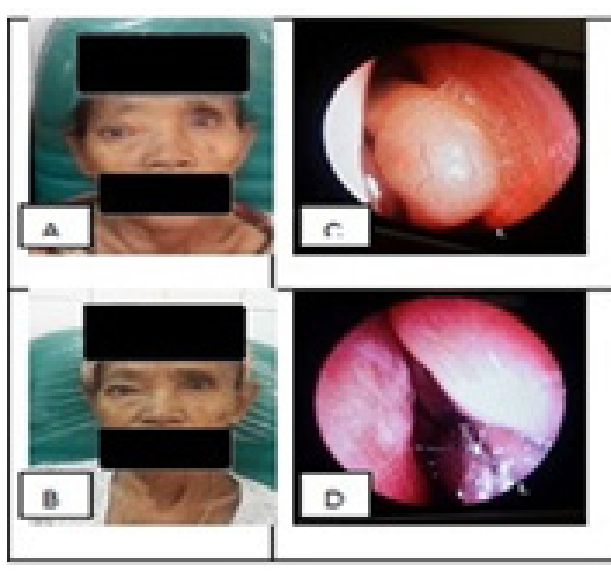

Gambar 1 Foto Klinis dan gambaran nasoendoskopi pasien.

A dan C sebelum operasi. B dan D sesudah operasi

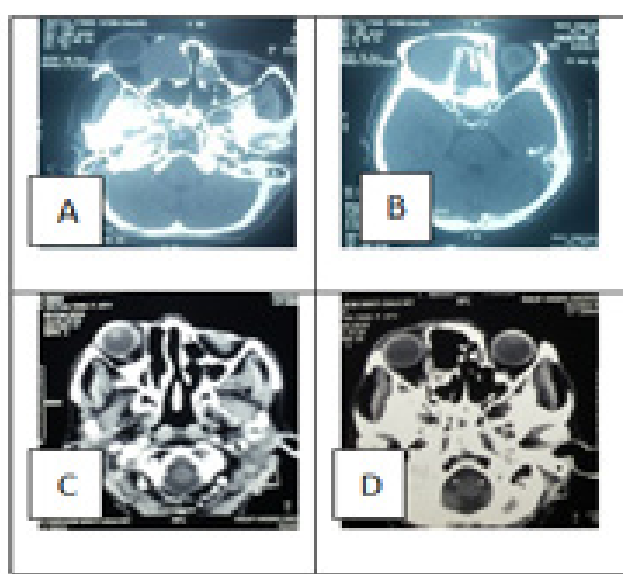

Gambar 2 Gambaran CT Scan pasien. A dan B sebelum operasi. C dan D setelah operasi 
Jarak antar pupil mengalami perbaikan berkurang $12 \mathrm{~mm}$. Hasil nasoendoskopi memperlihatkan mukosil tidak ditemukan, sekret tidak ada, osteum sinus maksilaris terbuka dan tidak ditemukan sinekia.

Pada gambaran CT scan paska operasi didapatkan massa mukosil sudah tidak ada. Deformitas yang terjadi akibat desakan mukosil berupa ruang sinus yang lebar pada sinus frontalis kanan berkurang ukuran setengahnya.

\section{Pembahasan}

Penyebab mukosil masih belum diketahui dengan jelas, sering dikaitkan dengan obstruksi osteum sinus yang terkena. Obstruksi dapat disebabkan proses kronis seperti rinosinusitis (infeksi atau alergi), polip sinonasal, trauma kraniofasial, riwayat operasi sebelumnya, tumor jinak atau tumor ganas. Pada pasien ini diduga obstruksi disebabkan proses kronis rinosinusitis sebagai dampak dari riwayat bekerja di pabrik pembakaran genteng selama beberapa puluh tahun.

Mukosil sinus paranasal banyak mengenai sinus frontalis $(60 \%)$ dan sinus ethmoidalis $(30 \%)$. Jarang mengenai sinus paranasal lainya seperti sinus maksilaris dan sinus sphenoid. Hal ini sesuai dengan kasus yang dilaporkan pada pasien ini. Prevalensi tertinggi terjadi pada dekade ke 3 dan 4 dan tidak ada perbedaan jenis kelamin.

Telusur literatur memperlihatkan mukosil sinus paranasal bilateral asimetris jarang terjadi. Vargese et al melaporkan kasus pertama mukosil bilateral asimetris pada tahun 2014 dimana lesi megenai sinus maksila dan sinus ethmoid pada sisi sebelahnya. Sehingga mungkin ini adalah kasus ke dua mukosil sinus paranasal bilateral asimetris.

Mukosil dapat meluas, mengubah bentuk dan mengabsorpsi dinding sinus, merubah struktur dan mempengaruhi struktur di sekitarnya seperti orbita dan intrakranial. Hal ini diyakini melibatkan proses yang osteolisis disebabkan oleh penurunan vaskularisasi tulang yang bertujuan menekan aktifitas mediator inflamasi, seperti sitokin (interleukin 1 dan 6), molekul adhesi pembuluh darah, dan prostaglandins. Pada pasien terlihat bahwa mukosil menyebabkan perluasan dinding sinus sehingga mempengaruhi struktur sinus dan orbita

CT adalah modalitas yang sering dipakai dalam pemeriksaan radiografi karena menggambarkan dengan jelas keterlibatan tulang dan adanya ekstensi orbita dan intrakranial, karena itu sangat berguna dalam operasi perencanaan. MRI dapat dilakukan apabila mukosil yang terbentuk akibat sekunder dari tumor sinonasal, dimana batas membran mukosil dapat terlihat jelas. Pemeriksaan CT scan mutlak dilakukan pada kasus ini untuk menggambarkan dengan jelas keterlibatan tulang dan adanya ekstensi orbita.

Biopsi sebelum operasi biasanya tidak dilakukan karena diagnosis mukosil cukup jelas secara klinis dan radiologis. Biopsi dapat dilakukan jika ada lesi yang mencurigakan.

Tatalaksana mukosil adalah pembedahan. Pendekatan transnasal endoskopik menjadi modalitas pilihan karena minimal invasif. Pendekatan transnasal endoskopik ini juga berkaitan dengan morbiditas yang rendah apabila tindakan yang direncanakan adalah marsupialisasi dan drainase mukosil.

Pascaoperasi masih didapatkan ruang sinus fronto-etmoid yang luas serta proptosis. Perlu dipikirkan untuk rencana rekonstruksi ruang sinus yang melebar dengan tujuan meminimalkan proptosis tanpa terjadi rekurensi mukosil.

\section{Daftar Pustaka}

1. Iseh KR. Endoscopic and external surgical approach to paranasal sinus mucocele. Journal of surgical technique and case report. 2010; 2: 49-53.

2. Aggarwal SK, Bhavana K, Keshri A, Kumar $\mathrm{R}$, Srivastava A. Frontal sinus mucocele with orbital complications: management by varied surgical approaches. Asian Journal Neurosurg. 2012;7(3):135-40.

3. Carvalho BV, Lopes ICC, Correa JB, Ramos LFM, Motta EGPC, Diniz RLFC. Typical and atypical presentations of paranasal sinus mucocele at computed tomography. Radio Bras Journal. 2013; 46(6): 372-75.

4. Punagi AQ, Mariani E. Pendekatan eksternal dan endonasal dengan atau tanpa endoskopi pada mukosil sinus frontal. Otorhino laryngologica Indonesiana. 2014; 44(2):15662.

5. Thiagarajan B,Arjunan K. Mucoceles of paranasal sinuses. WebmedCentral Otorhino laryngology.2012;3(4):WMC003263.

6. Tseng CC, Yin HC, Kao SC. Ophtalmic manifestations of paranasal sinus mucoceles. Journal of The Chinese Medical Association. 2005; 68(6): 260-264.

7. Chong AW, Prepageran $\mathrm{N}$, Rahmat $\mathrm{O}$, Subrayan V, Jalaludin MA. Bilateral asymmetrical mucocele of the paranasal sinuses with unilateral complications. ENTEar Nose \& Throat Journal. 2011; 90(2).

8. Aghakhanyan G, Lupi G, Frijia F, Hlavata $\mathrm{H}$, Lombardo F, Cori S, et.al. Delayed post 
Desti Kusmardiani : Bedah Sinus Endoskopik sebagai Pilihan Tata laksana Proptosis pada Mukosil Sinus Fronto-etmoidalis Asimetris Bilateral dengan Komplikasi

traumatic fronto-ethmoidal sinus mucocele evaluated with short and long TE MR Spectroscopy. The neuro radiology Journal. 2013;26:693-98.

9. Constantinidis J. Controversies in the management of frontal sinusmucoceles. Otorhinolaryngol Head Neck Surg Issue 2010; 42:8-14.

10. Neto CDP, Synderman CH. External approaches in sinus surgery. in : Bailey's head and neck surgery-otolaryngology 5th edition; 2014: 604-11. 